\title{
Research on the Crack Resistance at Low Temperature and the Mechanism of Semi-Flexible Pavement
}

\author{
Zheng Sun, Xi-xi Hou, Gui-ping He \\ Testing center of Shenzhen City Road Traffic Engineering, Shen Zhen, 518049 \\ 30598718@qq.com
}

\begin{abstract}
The crack resistance at low temperature of semi-flexible pavement was favorable, which prepared by waterborne epoxy-emulsified asphalt-cement as grouting material. While the $E / A$ is 0.6 , the maximum bending strain has reached $2662 \mu \varepsilon$, which is close to SMA-13. In the three-phase grouting system, asphalt was continuous phase, waterborne epoxy was dispersed phase, both of them bonded with cement.
\end{abstract}

Keywords-semi-flexible pavement; the crack resistance at low temperature; waterborne epoxy; compound grouting system

Cement pavement has the advantages of high strength, large bearing capacity and small temperature sensitivity, while its shortcomings are not comfortable drying and difficult repairing. Because of the advantages of excellent function and convenient repairing, asphalt pavement has become the mainstream of the development of the highway. However, our country has a vast territory and complicated climate characteristics, along with the canalized traffic, the disadvantages of poor bearing capacity, big temperature sensitivity and poor water stability have been the main factors to damage ${ }^{[1-4]}$.

Based on this background, semi-flexible pavement was appeared, which has both the advantages of cement pavement and asphalt pavement. Semi-flexible pavement is based on framework void asphalt mixture and filled with cement mortar ${ }^{[5-6]}$. The study generally indicated that semi flexible is a kind of price and good performance of pavement, but the current application indicate that semi flexible materials is easy to appear cracking damage. The main reason is the interface bonding force between cement and asphalt is only Van Edward force, which can't resist the internal stress by the shrinkage of cement and the thermal expansion of asphalt ${ }^{[7]}$. The most study on the modified measure of semi-flexible did not have the ideal effect. Using the high bonding force of waterborne epoxy and the flexibility of emulsified asphalt, the study has prepared the high performance semi-flexible material and researched its crack resistance at low temperature.

\section{RAW MATERIAL}

\subsection{Emulsified asphalt}

The research has selected the cationic slow crack SBR modified emulsified asphalt produced by Tipco Asphalt Public Company. The main quota is in table 1.
TABLE 1 MAIN PARAMETERS OF SBR MODIFIED EMULSIFIED ASPHALT

\begin{tabular}{|c|c|c|c|}
\hline \multicolumn{2}{|c|}{ Testing items } & Unit & Index \\
\hline \multicolumn{2}{|c|}{ Demulsification speed } & - & $\begin{array}{c}\text { Slow } \\
\text { crack }\end{array}$ \\
\hline \multicolumn{2}{|c|}{ Ionic charge } & - & $\begin{array}{c}\text { Cation } \\
(+)\end{array}$ \\
\hline \multicolumn{2}{|c|}{ Residue on 1.18mm sieve } & $\%$ & 0.06 \\
\hline \multirow{2}{*}{ Average size of emulsion } & $\mu \mathrm{m}$ & 3.8 \\
\hline \multirow{2}{*}{$\begin{array}{c}\text { Evaporation } \\
\text { residue }\end{array}$} & Solid content & $\%$ & 60.1 \\
\cline { 2 - 4 } & Penetration $\left(100 \mathrm{~g}, 25^{\circ} \mathrm{C}, 5 \mathrm{~s}\right)$ & $0.1 \mathrm{~mm}$ & 84 \\
\cline { 2 - 5 } & Softening point & ${ }^{\circ} \mathrm{C}$ & 53.0 \\
\hline \multirow{2}{*}{$\begin{array}{c}\text { Storage } \\
\text { stability }\end{array}$} & $1 \mathrm{~d}$ & $\mathrm{~cm}$ & 84 \\
\cline { 2 - 5 } & $5 \mathrm{~d}$ & $\%$ & 0.9 \\
\hline
\end{tabular}

\subsection{Cement}

The research has selected P.O42.5 portland cement by Huarun. The main quota is in table 2 .

TABLE 2 MAIN PARAMETERS OF CEMENT

\begin{tabular}{|c|c|c|c|c|c|c|}
\hline \multirow{2}{*}{$\begin{array}{c}\text { Surface } \\
\text { area } \\
\left(\mathrm{m}^{2} / \mathrm{kg}\right)\end{array}$} & \multirow{2}{*}{$\begin{array}{l}\text { Initial } \\
\text { setting } \\
\text { time } \\
(\mathrm{min})\end{array}$} & \multirow{2}{*}{$\begin{array}{l}\text { Final } \\
\text { setting } \\
\text { time } \\
(\mathrm{min})\end{array}$} & \multicolumn{2}{|c|}{$\begin{array}{l}\text { Compressive } \\
\text { strength } \\
(\mathrm{MPa})\end{array}$} & \multicolumn{2}{|c|}{$\begin{array}{c}\text { Flexural } \\
\text { strength } \\
(\mathrm{MPa})\end{array}$} \\
\hline & & & $3 d$ & $28 \mathrm{~d}$ & $3 d$ & $28 \mathrm{~d}$ \\
\hline 325 & 245 & 400 & 30.5 & 44.0 & 5.00 & 6.70 \\
\hline
\end{tabular}

1.3 Waterborne epoxy and hardening agent

Different preparation process means different electricity and particle size, which may significant effect the consolidation and homogeneity of the binder system. The research showed that the cationic waterborne epoxy will reunite with cement and anionic waterborne epoxy will reunite with cationic emulsified asphalt. The research used E51 waterborne epoxy and hardening agent, there main quota is in table 3 . 
TABLE 3 MAIN PARAMETERS OF WATERBORNE EPOXY AND HARDENING AGENT

\begin{tabular}{|c|c|c|c|}
\hline $\begin{array}{c}\text { Testing } \\
\text { items }\end{array}$ & $\begin{array}{c}\text { operation } \\
\text { time } / 25^{\circ} \mathrm{C}\end{array}$ & $\begin{array}{c}\text { Average size of } \\
\text { emulsion } / \mu \mathrm{m}\end{array}$ & $\begin{array}{c}\text { Solid } \\
\text { content } \\
/ \%\end{array}$ \\
\cline { 1 - 1 } $\begin{array}{c}\text { waterborne } \\
\text { epoxy }\end{array}$ & $3.0 \mathrm{~h}$ & 0.22 & 100 \\
\cline { 1 - 1 } $\begin{array}{c}\text { hardening } \\
\text { agent }\end{array}$ & & & 40 \\
\hline
\end{tabular}

\subsection{Aggregate}

The research used aggregate from Ping-hu, Shen zheng. The Coarse aggregate is dolerite with $2.712 \mathrm{~g} / \mathrm{cm}^{3}$ apparent density, $0.45 \%$ water-absorbing capacity, $13.5 \%$ crush value and $15.2 \%$ L.A. Abrasion. The fine aggregate is also dolerite with $2.705 \mathrm{~g} / \mathrm{cm}^{3}$ apparent density, $0.75 \%$ water-absorbing capacity. The filler used common limestone powder with $2.726 \mathrm{~g} / \mathrm{cm}^{3}$ apparent density.

\subsection{Asphalt}

The matrix asphalt mixture is framework-void structure. Its shearing strength was provided by the internal friction angle of aggregate. In order to enhance the shearing strength, the research chose high viscosity modified asphalt with 48 penetration degree, $95^{\circ} \mathrm{C}$ softening point, $65 \mathrm{~cm}$ ductility $\left(5^{\circ} \mathrm{C}\right)$ and $86500 \mathrm{~Pa} \cdot \mathrm{S}$ dynamic viscosity $\left(60^{\circ} \mathrm{C}\right)$.

\section{MIX DESIGN}

\subsection{Mix design of the mortar}

The study has proposed a complex system based on organic-inorganic composite grouting material. In the system, cement had the effect of absorbing water from the emulsion, cured epoxy resins and asphalt. It's strength guarantee of the grouting material. Waterborne epoxy played the role of improving the interface bonding strength between mortar and matrix asphalt mixture. Because of brittleness, it can't be continuous phase in the grouting system. Therefore, in the grouting material, asphalt was continuous phase, waterborne epoxy as bonding modifier and cement as strength modulators.

Based on the above design ideas, the study ensured the max ratio between waterborne epoxy(E) and emulsified asphalt(A) as 1.0. Fixing E/A as 1.0, testing the homogeneity of grouting system under different $\mathrm{C} / \mathrm{A}$ and ensuring min cement ratio(C/A) as 0.4 . Using this design, the homogeneity was 0.958 . Fixing E/A as 1.0 , using C/A as 0.4 for a starting point, testing the resilient modulus of grouting system under different $\mathrm{C} / \mathrm{A}$ and ensuring max cement ratio(C/A) as 0.7 . Using this design, the resilient modulus was $5010 \mathrm{MPa}$. Fixing $\mathrm{C} / \mathrm{A}$ as 0.55 and $\mathrm{E}$ (hardening agent)/E as 1.0 , and testing crack resistance under different $\mathrm{E} / \mathrm{A}$.

\subsection{Mix design of matrix asphalt}

Referred to porous asphalt mixture (OGFC) design method, controlled key sieve of $2.36 \mathrm{~mm}$ and $4.75 \mathrm{~mm}$, the study used volume method to design matrix asphalt, while the porosity is $30 \%$ and connected porosity more than $23 \%$.

\section{STUDY ON CRACK RESISTANCE AT LOW TEMPERATURE}

The main cracking reason of semi-flexible pavement included two aspects. First, as for temperature sensitive materials, the asphalt had the characteristics of low temperature brittleness. With the decrease of temperature, its stiffness modulus increased, strength enhanced, but the ability of resistance reduced. Limited by the friction force from the under layer asphalt, the distortion of surface layer asphalt would translate to temperature shrinkage stress $^{[8-10]}$. Then, cement hydration would cause shrinkage stress. While the two stress excessed their tensile strength or interface bonding strength, the semi-flexible will be cracked. The study used small beam bending test $\left(-10^{\circ} \mathrm{C}\right)$ to research on the cracking performance of semi-flexible material. The testing result was in table 4 .

\section{TABLE 4 TESTING RESULT OF CRACKING} PERFORMANCE

\begin{tabular}{|c|c|c|c|}
\hline E/A & $\begin{array}{c}\text { Flexural } \\
\text { strength } \\
(\mathrm{MPa})\end{array}$ & $\begin{array}{c}\text { Max bending } \\
\text { strain }(\mu \varepsilon)\end{array}$ & $\begin{array}{c}\text { Bending } \\
\text { stiffness } \\
\text { modulus }\end{array}$ \\
\hline 0.0 & 7.28 & 2083 & 3495 \\
\hline 0.2 & 7.01 & 2229 & 3145 \\
\hline 0.4 & 6.42 & 2523 & 2545 \\
\hline 0.6 & 6.18 & 2662 & 2322 \\
\hline 0.8 & 6.12 & 2374 & 2578 \\
\hline 1.0 & 6.08 & 2074 & 2932 \\
\hline SMA-13 & 8.26 & 2892 & 2856 \\
\hline $\begin{array}{c}\text { Semi } \\
\text { flexible } \\
\text { material } \\
\text { Prepared } \\
\text { bir }\end{array}$ & 8.02 & 950 & 8442 \\
\hline
\end{tabular}

With bigger max bending strain and smaller flexural strength, the crack resistance at low temperature was better. Without emulsified asphalt and waterborne epoxy, the max bending strain was less than $1000 \mu \varepsilon$. Just with emulsified asphalt, the max bending strain was around $2000 \mu \varepsilon$, which was worse than SMA-13. Adding emulsified asphalt, the stiffness of semi flexible material was significantly reduced. The main reason was the different temperature shrinkage coefficient between asphalt and cement hydration products. With the waterborne epoxy increasing, the max bending strain increased first and then decreased, bending stiffness modulus decreased first and then increased. That means the crack resistance at low temperature increased first and then decreased. While the E/A was 0.6, the cured epoxy would fix the asphalt and cement hydration products. So, the bonding strength from cured epoxy would offset the temperature shrinkage stress from asphalt and the dry shrinkage from cement. However, when the E/A was over 0.6 , redundant cured epoxy may be free components. Because of the low temperature brittleness of cured epoxy, the crack resistance at low temperature of the semi-flexible material was also reduced. 


\section{MECHANISM STUDY}

Filled waterborne epoxy-emulsified asphalt-cement grouting material into matrix asphalt, the crack resistance at low temperature of the semi-flexible material was improved significantly. The study used SEM to test the microstructure of grouting system and analysis the disposition of three phases. The results of SEM testing were given in Fig.1-Fig.4.

From Fig.1, cement hydration products was consist of cluster C-S-H hydrogels and needle shaped ettringite, which had obvious pore. Compared Fig.2 with Fig.1, the grouting system became more compact. The non-hydrated cement and C-S-H hydrogels entwined with gray part of cured epoxy. In Fig.2, there was no ettringite exit. Compared Fig.3 with Fig.1, the grouting system still had a lot of pore. Hydration products grown on the asphalt, non-hydrated cement existed alone as grain. Fig.4 was microcosmic pattern of the three phases bonding system. The main structure was that gray and smooth part of asphalt as continuous phase, crinkled part of cured epoxy as dispersed phase and bright cluster of C-S-H hydrogels as bonding composition. Compared Fig. 4 with Fig. 2 and Fig.3, the grouting system became more compact and without obvious pore.

Based on the analysis about the microcosmic pattern, the continuous phase changed into asphalt, which had viscoelastic properties. On the one hand, the coordination deformation ability between grouting material and matrix asphalt was enhanced. On the other hand, the cured epoxy reinforced the interface adhesion between grouting material and matrix asphalt, which enhanced the crack resistance of semi-flexible material.

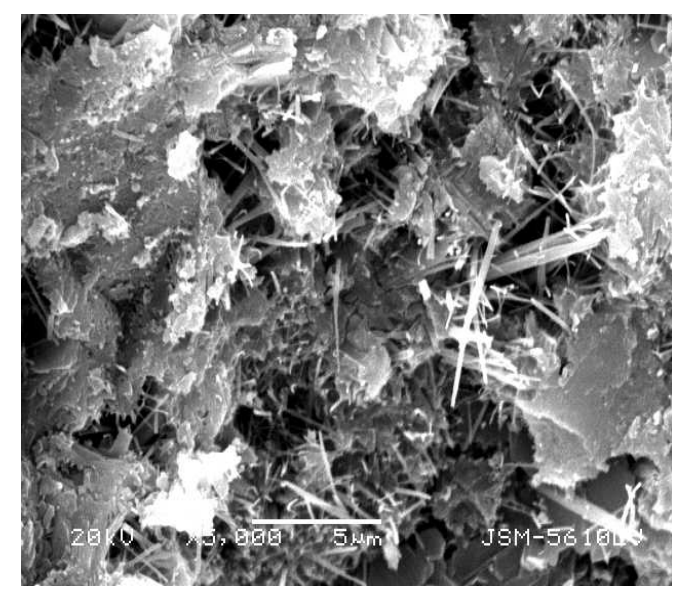

Fig.1 Pure cement hydration 28d SEM(X5000)

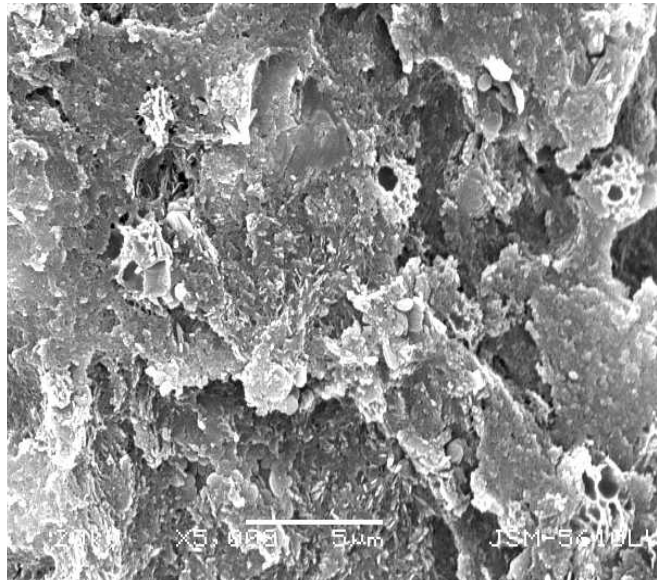

Fig.2 C+E 28d SEM(X5000)

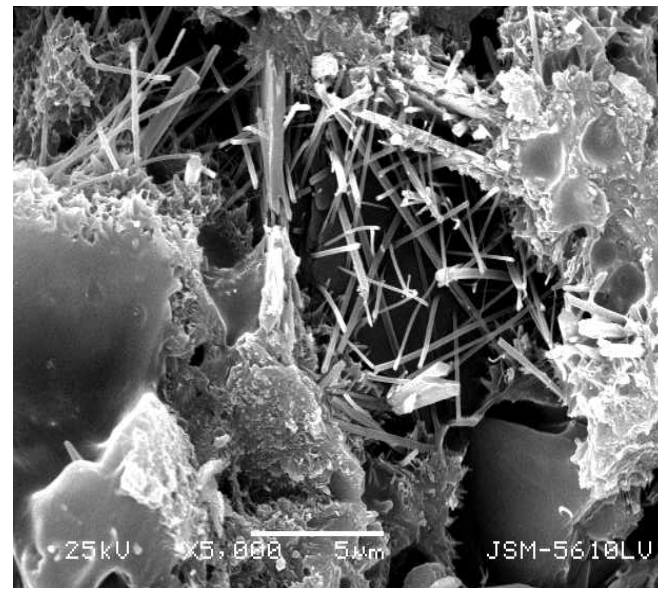

Fig.3 C+A 28d SEM(X5000)

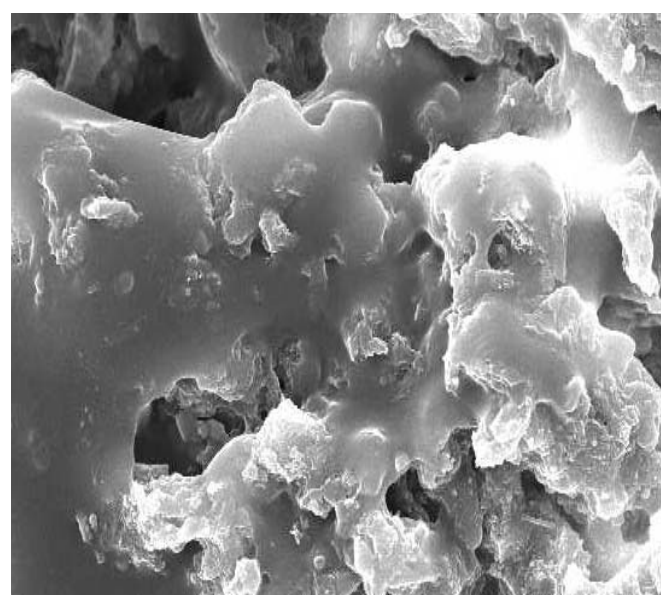

Fig.4 C+E+A 28d SEM(X5000)

\section{CONCLUSION}

(1) Compared with common semi-flexible material, the semi-flexible prepared by waterborne epoxy-emulsified asphalt-cement grouting material had better crack resistance at low temperature. While the E/A is 0.6 , the maximum bending strain has reached $2662 \mu \varepsilon$, which is close to SMA-13.

(2) Mechanism study indicated that, in the grouting 
material, asphalt was continuous phase, waterborne epoxy as bonding modifier and cement as strength modulators. The structure could reduce the shrinkage stress of cement and enhance the interface adhesion between grouting material and matrix asphalt.

\section{ACKNOWLEDGEMENT}

This material is based upon work supported by Shenzhen Committee of Science and Technology Innovation (Project number: CXZZ20140820151319424).

\section{REFERENCES}

[1] Pen bo. Study on Geometric Characteristics and Structure of Asphalt Mixture Aggregate[D]. Doctor thesis of Chang'an University, 2008.

[2] Ni Zheng-min. The composite temperature stability study on Perfusion rubber powder semi-flexible pavement[D]. Master thesis of Guangxi University of science and technology, 2013.

[3] Du Shun-cheng. Study of Evaluation Index of High-temperature Stability and Design Methodology for Asphalt Mixture[D]. Doctor thesis of Chang'an University, 2007.

[4] Zhang Da-ke, Cheng Chang-qing, Wu Guo-xiong. Water Susceptibility and Crack Resistance at LowTemperature of Semi-flexible Pavement $[\mathrm{J}]$. Journal of Chongqing Jiaotong University, 2007,26(3):55-57.

[5] Wu Dan. Research on fatigue property of semi-flexible pavement[D]. Master thesis of Chongqing Jiaotong University, 2009.

[6] Zhang Rong-kun. Research and Application on High-performance pouring Semi-flexible Pavement Material[D]. Master thesis of Wuhan University of Technology, 2009.

[7] Huang Chong. Research on Volume-stability and Crack-resistance of Semi-flexible Pavement Material[D]. Master thesis of Wuhan University of Technology, 2010.

[8] Zhou Xiao-jun, Shen Li-juan. Knowledge about structure and strength of the asphalt mixture[J]. Private science and technology, 2008, (2): 156.

[9] Setyawan.Development of Semi-Flexible Heavy-Duty Pavements[J]. PhD thesis.University of Leeds, 2003, 143(5):72 84.

[10] Shen Fan. Research on Composite Steel Bridge Deck Pavement of Cement-Emulsifying Asphalt and waterborne Epoxy[D]. Doctor thesis of Wuhan University of Technology, 2012. 